\title{
A new genus of sea louse (Copepoda: Siphonostomatoida: Caligidae) parasitic on the bluespine unicornfish (Naso unicornis)
}

\author{
Geoffrey A. Boxshall \\ Department of Zoology, The Natural History Museum, Cromwell Road, London SW7 5BD, UK
}

Key words: taxonomy, parasitic copepod, fish host, Alanlewisia gen. n., Caligidae, Naso unicornis

\begin{abstract}
A new genus, Alanlewisia, of the family Caligidae is established to accommodate a sea louse species originally, but tentatively, placed in the genus Lepeophtheirus by Lewis (1967). The type species is Alanlewisia fallolunulus (Lewis, 1967) comb. n., which is redescribed in detail based on new material collected from bluespine unicornfish, Naso unicornis (Forsskål), caught off New Caledonia in the South Pacific. This species was originally described by Lewis (1967) under the binomen Lepeophtheirus? fallolunulus from the same host species collected in Hawaii. This species was subsequently transferred to the genus Anuretes by Ho and Lin (2000). Lewis was uncertain of the generic placement primarily because of the possession, in the females only, of paired lunule-like structures on the ventral surface of the modified frontal plates. In both sexes the first swimming leg is biramous, with a well-developed endopod bearing 2 long, sparsely-plumose setae, and the third leg has a 2-segmented exopod. This combination of characters serves to differentiate the new genus from existing genera. Preliminary phylogenetic analysis suggests that the new genus represents an early offshoot from the main caligid lineage, basal to the Paralebion-TuxophorusCaligus clade identified by Boxshall and Justine (2005).
\end{abstract}

In 1967 Lewis described a new species of caligid copepod under the binomen Lepeophtheirus? fallolunulus from Hawaii. Its host was the bluespine unicornfish, Naso unicornis (Forsskål), a member of the family Acanthuridae, a common family of reef-fishes which includes the surgeon fishes and tangs as well as the unicorn fishes (Froese and Pauly 2007). Lewis (1967) was uncertain of the generic placement of this species, preferring to include it tentatively in the genus Lepeophtheirus von Nordmann, 1832 which it resembled in most respects. This species was subsequently transferred to the genus Anuretes Heller, 1865 by Ho and Lin (2000) as Anuretes fallolunulus (Lewis, 1967), despite the possession of a defined abdomen.

The family Caligidae currently comprises well in excess of 400 described species classified in 33 genera. This total includes the recently established genus, Avitocaligus Boxshall et Justine, 2005, in addition to the five genera formerly attributed to the family Euryphoridae since these two families were formally synonymised by Boxshall and Halsey (2004). The caligid affinities of the new genus are confirmed by the possession of a biramous first swimming leg in combination with the caligid cephalothorax incorporating the first to third pedigerous somites. It is described below and its classification within the Caligidae is revisited in the light of the novel data this new study provides.

\section{MATERIALS AND METHODS}

Dissected appendages were observed as temporary mounts in lactophenol on a Leitz Diaplan microscope equipped with differential interference optics. Drawings were made with the aid of a camera lucida. Terminology follows Boxshall (1990) and Huys and Boxshall (1991). Material for scanning electron microscopy was washed in distilled water, dehydrated through graded acetone series, critical point dried using liquid carbon dioxide as the exchange medium, mounted on aluminium stubs and sputter coated with palladium. Coated material was examined on a Phillips XL30 Field Emission Scanning Electron microscope operated at $5 \mathrm{kV}$.

Eleven Naso unicornis with a fork length ranging from 390 to $540 \mathrm{~mm}$ (weight 1,200 to $3,000 \mathrm{~g}$ ) collected by J.-L. Justine around various islets off Noumea on the coast of southern New Caledonia were examined. Six fish were infected $(55 \%$ prevalence) and the infected hosts were taken at the following stations: JNC1516, Îlot Goëland (22²2'S, 166 23 'E), 12 April 2005; JNC1552-1553, Îlot Goëland, 28 June 2005; JNC1580-1581, Îlot La Régnière (22 $\left.{ }^{\circ} 19^{\prime} \mathrm{S}, 166^{\circ} 20^{\prime} \mathrm{E}\right), 8$ September 2005; and JNC2155, Récif Tué (22 $\left.{ }^{\circ} 19^{\prime} \mathrm{S}, 166^{\circ} 29^{\prime} \mathrm{E}\right)$, 27 March 2007. Nineteen females, 5 males and 2 preadult females of the copepod were collected: $60+$, $1 \delta^{\hat{\gamma}}$ from JNC1516; 5 우 $ᄋ$, 1 ㄱ, 1 pre-adult $q$ from JNC1552; 2 우 from $\mathrm{JNC} 1553 ; 2 ㅇ+q, 1 \delta^{\lambda}$ from $\mathrm{JNC} 1580 ; 1 \delta^{\lambda}, 1$ pre-adult $q$ from $\mathrm{JNC} 1581$, and $2 q+$ from JNC2155.

\section{RESULTS}

\section{Alanlewisia gen. $\mathrm{n}$.}

Diagnosis. Body dorsoventrally flattened, comprising caligiform cephalothorax, incorporating first to third pedigerous somites, free fourth pedigerous somite, a broad genital complex, and a free 1-segmented abdomen. Caudal rami with 6 setae. Paired frontal plates with ventral lunule-like structure in female, lacking such structures in male. Nauplius eye present. Antennule 2- 

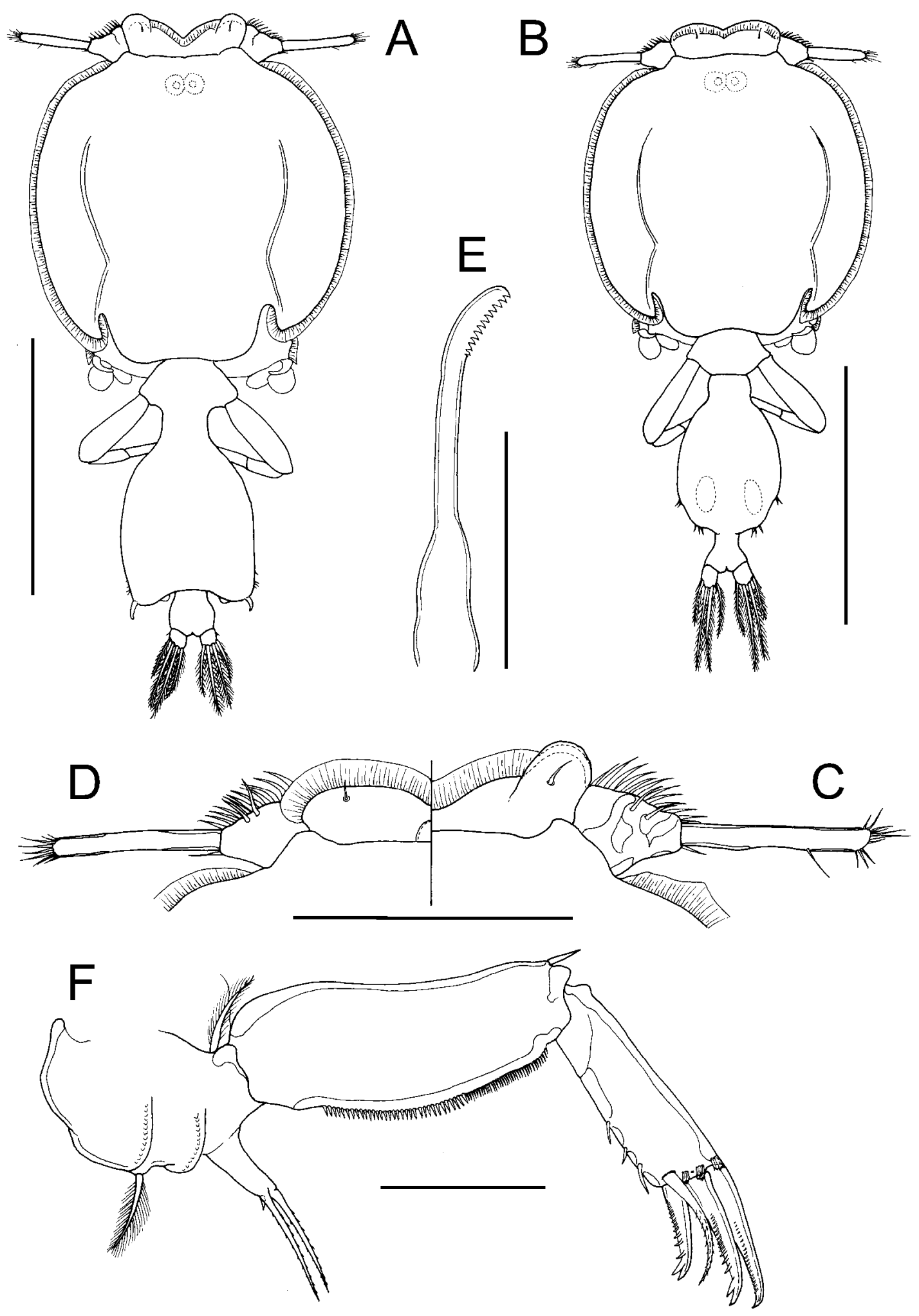

Fig. 1. Alanlewisia fallolunulus (Lewis, 1967). A - female habitus, dorsal; B - male habitus, dorsal; C - antennule and frontal plate on right side of adult female, dorsal; $\mathbf{D}$ - antennule and frontal plate on left side of adult male, dorsal; $\mathbf{E}$ - mandible, female; F- first leg, female, ventral view. Scale bars: A, B = $1 \mathrm{~mm} ; \mathrm{C}, \mathrm{D}=0.5 \mathrm{~mm} ; \mathrm{E}, \mathrm{F}=100 \mu \mathrm{m}$. 

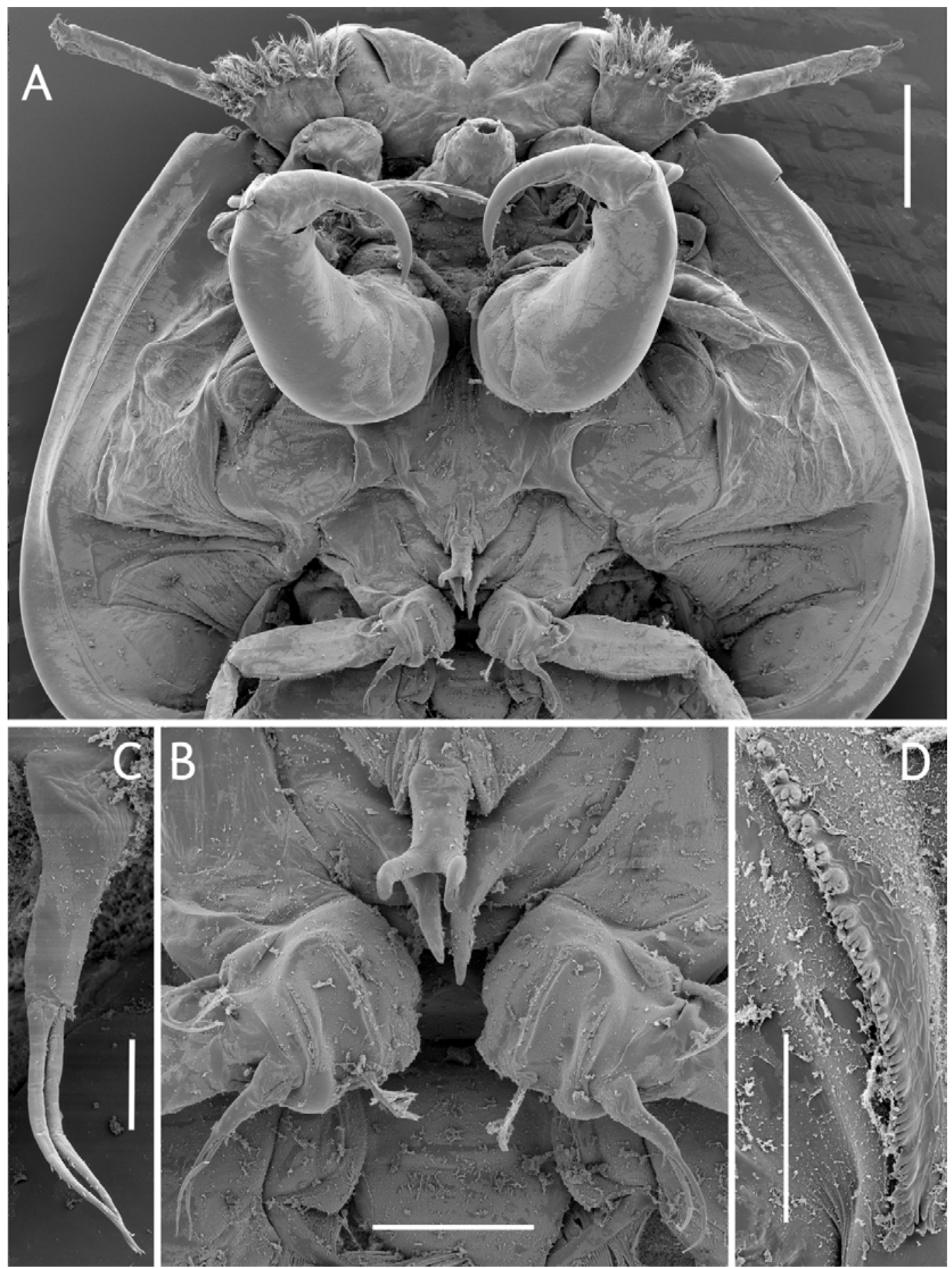

Fig. 2. Alanlewisia fallolunulus (Lewis, 1967), female, scanning electron micrographs. A - anterior part of cephalothorax, ventral; B - sternal furca and base of first legs, ventral; $\mathbf{C}$ - endopod of leg 1, ventral; $\mathbf{D}$ - detail of ornamentation on sympod of first leg, ventral view. Scale bars: $A=200 \mu \mathrm{m} ; \mathrm{B}=100 \mu \mathrm{m} ; \mathrm{C}, \mathrm{D}=20 \mu \mathrm{m}$.

segmented, second segment elongate; both segments with uneven sclerotization. Antenna uniramous, comprising coxa, basis and laterally directed subchela formed by fusion of endopod and distal claw; exopod absent. Postantennal process present. Oral cone tapering, formed by both labrum and labium. Mandible stylet-like. Maxillule bilobed, with basal portion incorporated into body wall; anterior lobe papillate, bearing 3 setae; posterior lobe an unarmed spinous process. Maxilla comprising syncoxa (lacertus) and basis (brachium) bearing calamus and canna distally. Maxilliped with massive protopod (corpus) and distal subchela repre- 
senting fused endopodal segments plus terminal claw. Sternal furca present, appearing double due to presence of pair of spinous processes on ventral cephalothoracic wall adjacent to furca. Swimming leg 1 biramous, with exopod 2-segmented and well developed but with vestigial inner setae on distal segment; unsegmented endopod armed with 2 sparsely-plumose setae and a short spine. Inner plumose seta (derived from basis) present on leg 1. Leg 2 biramous, with protopod comprising coxa and basis; both rami 3-segmented. Leg 3 with coxa and basis fused into flattened sympod; leg pair connected by expanded intercoxal sclerite and forming broad plate sealing rear margin of cephalothorax; both rami 2-segmented due to failure to separate of second and third segments. Fourth leg uniramous; coxa and basis fused, exopod 2-segmented. Spine and seta formula as follows:

$\begin{array}{lllll} & \text { Coxa } & \text { Basis } & \begin{array}{l}\text { Exopodal } \\ \text { segments }\end{array} & \begin{array}{l}\text { Endopodal } \\ \text { segments }\end{array} \\ \text { Leg 1 } & 0-0 & 1-1 & \text { I-0; III,I,3* } & 2, \text { I } \\ \text { Leg 2 } & 0-1 & 1-0 & \text { I-1; I-1; III,5 } & 0-1 ; 0-2 ; 6 \\ \text { Leg 3 } & 0-1 & 1-0 & \text { I-1; IV,5 } & 0-0 ; 6 \\ \text { Leg 4 } & 0-0 & 1-0 & \text { I-0; IV } & -\end{array}$

Leg 5 comprising isolated outer protopodal seta, plus lobe on posterolateral margin of genital complex bearing 3 plumose setae; curved J-shaped process present on posterior margin of genital complex medial to leg 5 . Male legs 5 and 6 both comprising marginal lobes bearing 3 plumose setae. Egg sacs linear, uniseriate.

Type species: Lepeophtheirus? fallolunulus Lewis, 1967 by original designation.

E t y m o log y: The generic name is formed in honour of Dr.

Alan G. Lewis, the discoverer and original describer of the type species.

Remarks. In caligids the frontal plates are typically provided with marginal membrane and comprise the anterior sector of the cephalothoracic sucker, which is defined laterally by the long strips of marginal membrane along the lateral edges of the expanded dorsal cephalothoracic shield, and is delimited posteriorly by the broad, apron-like third swimming legs. A distinctive feature of the new genus is the modification of the paired frontal plates in the female only. The male frontal plates are entirely unmodified, as in species of Lepeophtheirus, for example. In combination with the welldeveloped, unsegmented but bisetose endopod of leg 1 and the reduced 2-segmented exopod of leg 3, these features indicate that this species represents a new genus on a lineage basal to the Caliginae-grouping which is characterized by the possession of true lunules on the frontal plates, and basal to the Lepeophtheirinae-lineage which has a vestigial endopod on leg 1 and lacks lunules or any lunule-like modification of the frontal plates in either sex. The new genus lies basal to the Paralebion-
Tuxophorus-Caligus clade identified by Boxshall and Justine (2005) in the preliminary analysis of relationships at the base of the Caligidae.

\section{Alanlewisia fallolunulus (Lewis, 1967) comb. n.}

\section{Redescription}

Female

Figs. 1A, C, E, F, 2, 3, 4, 5A, 6A-D

Female body (Fig. 1A) dorsoventrally flattened; mean body length $2.90 \mathrm{~mm}$, (range 2.69-3.05 mm, based on 10 specimens); maximum width of cephalothoracic shield $1.41 \mathrm{~mm}(1.34-1.57 \mathrm{~mm})$. Cephalothorax caligiform, incorporating first to third pedigerous somites; dorsal cephalothoracic shield provided with conspicuous marginal membrane laterally (Fig. 2A). Frontal plates provided with marginal membrane medially but produced into rounded expansions laterally (Fig. 1C): single sensilla present dorsally on lateral expansion of each frontal plate. Ventrally (Fig. 3A, B) separation of expanded, fronto-lateral region from medial region marked by flap of integument. Surface of expansion showing concentric markings ventrally, following curved anterior margin of frontal plate expansion.

Nauplius eye visible dorsally through cuticle (Fig. 1A). Fourth pedigerous somite forming narrow 'waist' between cephalothorax and genital complex. Genital complex longer than wide; mean length $1.02 \mathrm{~mm}(0.87-$ $1.12 \mathrm{~mm})$ and mean width $0.84 \mathrm{~mm}(0.69-0.95 \mathrm{~mm})$. Abdomen comprising single somite (Fig. 1A) about as wide as long, mean length $0.16 \mathrm{~mm}(0.14-0.18 \mathrm{~mm})$ and mean width $0.18 \mathrm{~mm}(0.17-0.19 \mathrm{~mm})$. Caudal rami dorsoventrally flattened, armed with 6 plumose setae (Fig. 1A).

Antennule 2-segmented (Figs. 1C, 2A); first segment with irregular secondarily thickened areas of cuticle: second segment elongate, mid zone with thinner cuticle: first segment armed with total of 27 irregularly plumose or hirsute setae, second segment with 1 posterior seta plus apical array of 12 setal elements.

Antenna uniramous (Fig. 4A), comprising coxa, basis and curved, laterally directed subchela formed by fusion of endopod and distal claw. Coxa unarmed. Basis unarmed but with swelling near inner distal corner. Subchela forming strong claw bearing 2 setae proximally. Postantennal process ornamented with fine surface striations (Fig. 5C); 2 multisetulate papillae present on basal part of process plus 1 on adjacent surface; small tapering process located on ventral cephalothoracic surface just medial to process (Fig. 4A).

Oral cone tapering distally, with narrow apical opening (Fig. 3A). Mandible stylet-like (Fig. 1E) bearing 12 teeth on one side near apex.

Maxillule with basal portion incorporated into ventral cephalothoracic wall; anterior papilla bearing 3 unequal setae; posterior lobe forming tapering spiniform process (Fig. 4A). 

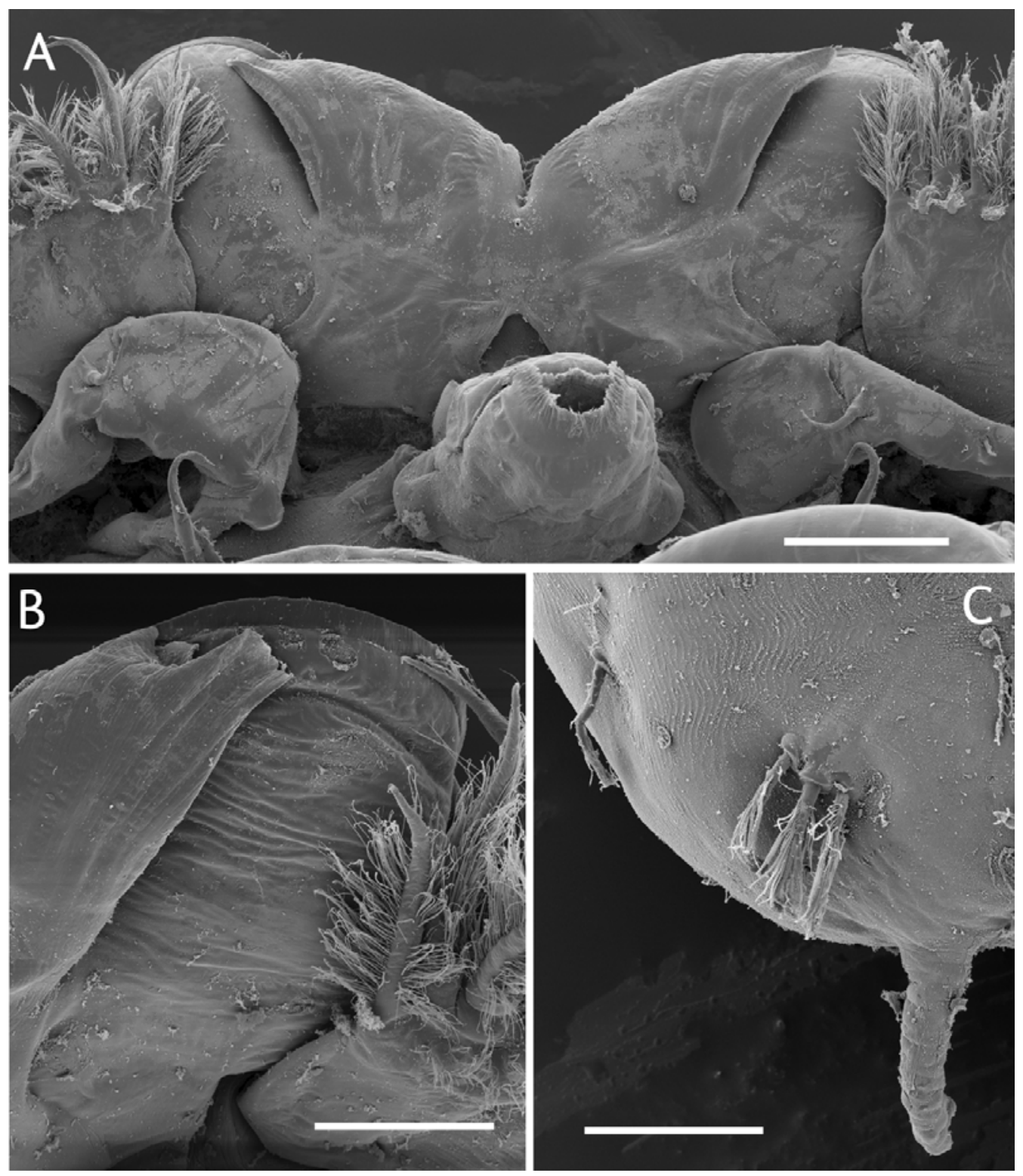

Fig. 3. Alanlewisia fallolunulus (Lewis, 1967), female, scanning electron micrographs. A - frontal plates, ventral; B - detail of lunule-like structure on ventral surface of right frontal plate; $\mathbf{C}-\operatorname{leg} 5$ in situ, ventral. Scale bars: A = $100 \mu \mathrm{m} ; \mathrm{B}, \mathrm{C}=50 \mu \mathrm{m}$.

Maxilla (Fig. 6A) well developed, brachiform, comprising unarmed syncoxa (lacertus) and basis (brachium) bearing long calamus and shorter canna at apex, plus flabellum just distal to mid-length on anterior margin. Calamus about 2.5 times longer than canna. Flabellum narrow, comprising deeply serrated membrane.

Maxilliped comprising massive corpus (Figs. 2A, 4B) and distal subchela representing fused endopodal segments plus heavily sclerotized terminal claw. Corpus unarmed but with slight swelling in myxal area, opposing tip of claw, and ridged pad proximally on posterior surface. Subchela subdivided by irregular suture line; bearing single seta about at level of suture.

Sternal furca present, appearing double (Figs. 2B, $5 \mathrm{~A})$ due to presence of pair of spinous processes on ven- tral cephalothoracic wall adjacent to furca. Furca with simple, flanged tines.

Leg 1 biramous (Fig. 1F) with rectangular sympod bearing outer and inner plumose setae, inner located near to origin of endopod; sympod ornamented with two parallel ridges (Figs. 1F, 2D) orientated anteroposteriorly on ventral surface, each comprising series of multicusped denticles. Exopod 2-segmented; large, robust first segment carrying outer distal spine, lacking inner seta but with inner marginal row of spinules; second segment with 3 distal margin spines, outermost simple, second and third with bifid tips (Fig. 1F), plus inner distal angle seta located on ventral surface close to distal margin, and 3 vestigial setae on inner margin, represented by short, spine-like elements. Endopod un- 

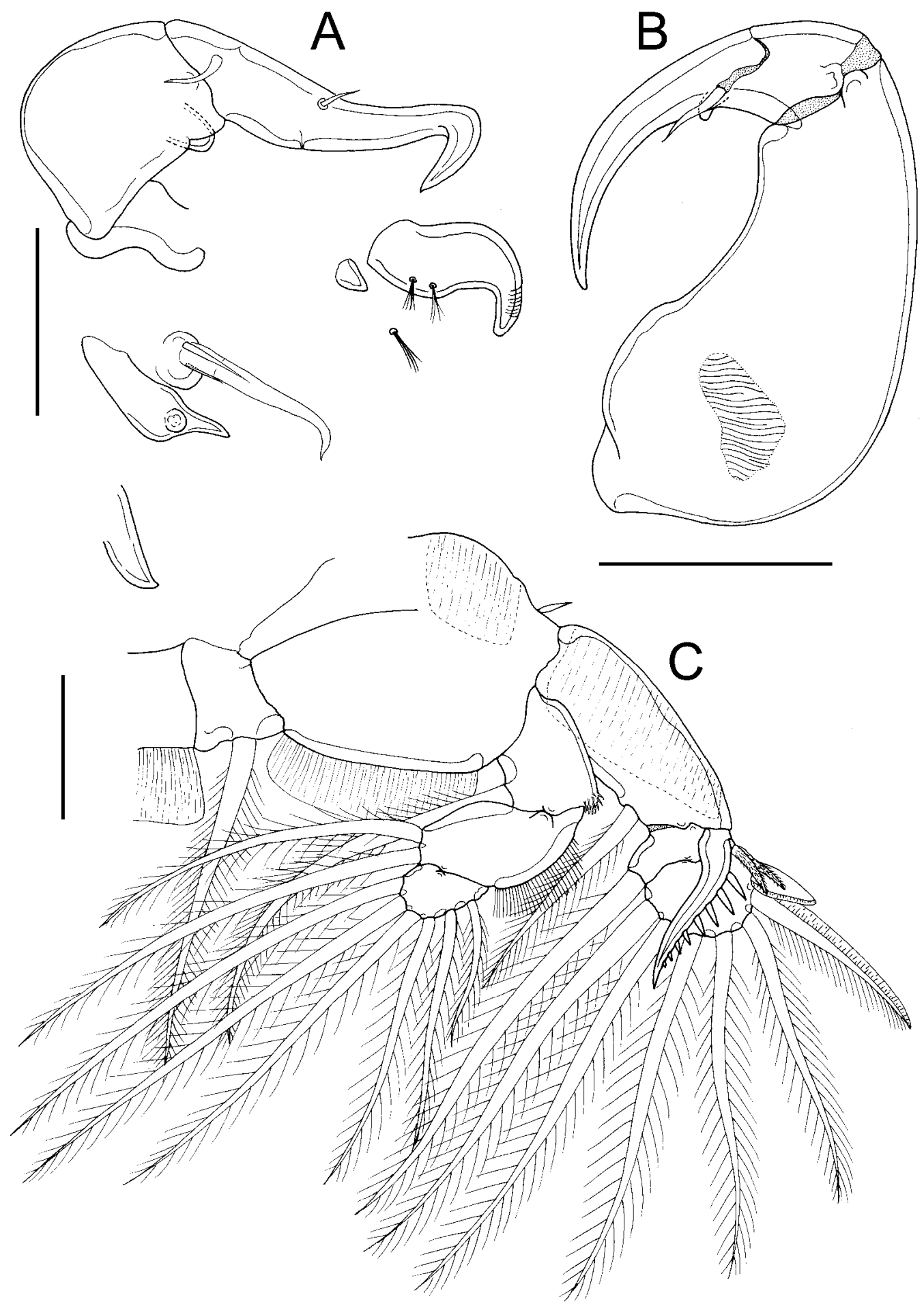

Fig. 4. Alanlewisia fallolunulus (Lewis, 1967), female. A - antenna, postantennal process, maxillule, and post-oral process, ventral in situ; $\mathbf{B}$ - maxilliped, posterior; $\mathbf{C}-\operatorname{leg} 2$, ventral. Scale bars: A, C $=100 \mu \mathrm{m} ; \mathrm{B}=200 \mu \mathrm{m}$.

segmented, tapering towards tip (Fig. 2B, C); armed with 2 sparsely plumose setae and short spine apically.

Leg 2 biramous (Fig. 4C); protopod comprising coxa and basis; coxa short, bearing long, plumose seta on posterior margin; basis long, armed with short, naked, outer distal spine and provided with extensive flap of marginal membrane along inner margin and another reflexed flap of membrane dorsally, along outer margin (Fig. 4C). Both rami 3-segmented. First exopodal segment elongate, with large outer spine reflexed over dis- 

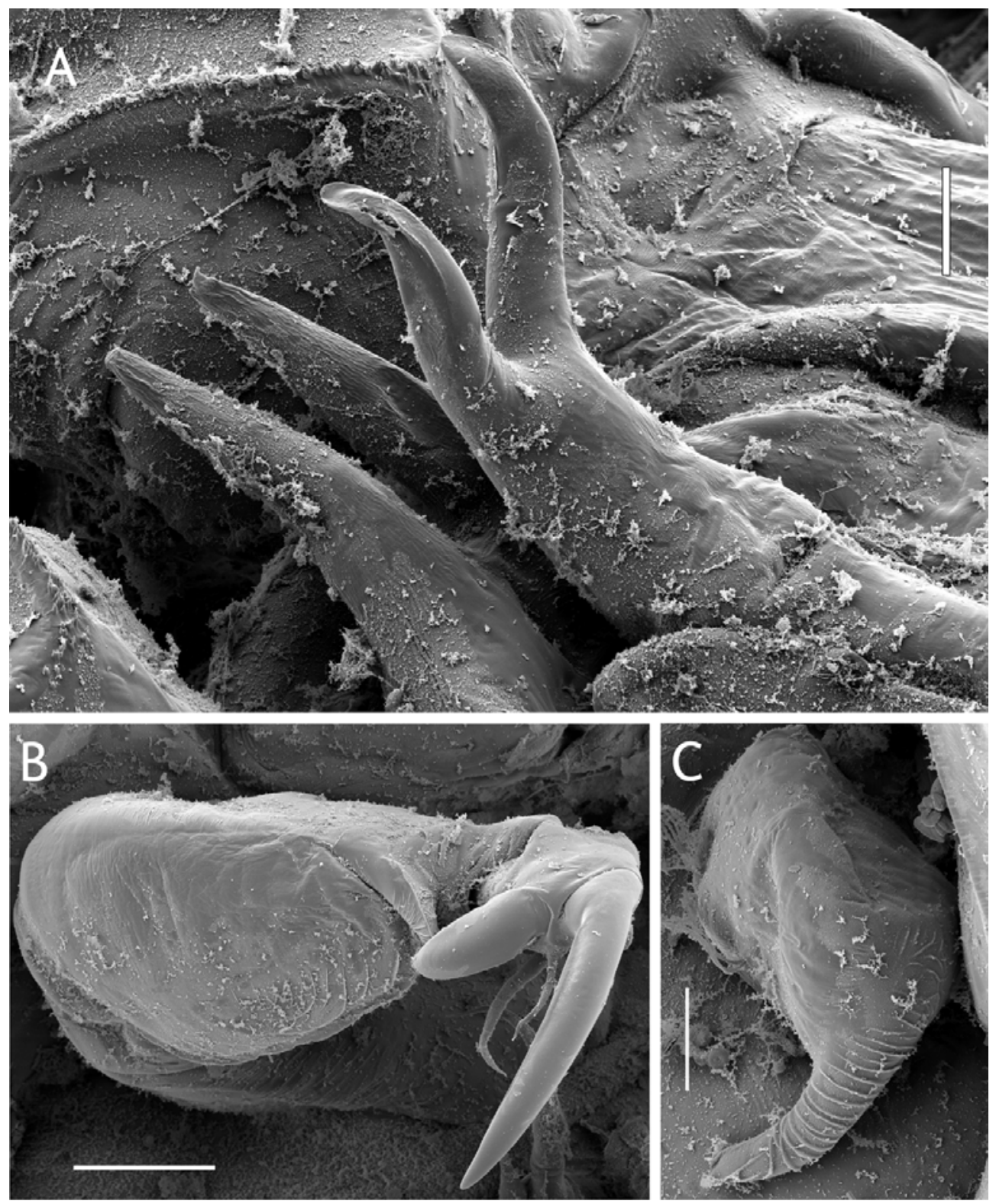

Fig. 5. Alanlewisia fallolunulus (Lewis, 1967), scanning electron micrographs. A - female sternal furca, lateral view in situ; B - male antenna, ventral; $\mathbf{C}$ - male postantennal process, ventral view in situ. Scale bars: A, C = $20 \mu \mathrm{m}$; B = 50 $\mu \mathrm{m}$.

tal segments, ornamented with single row of conspicuous spinules (Fig. 4C), and inner plumose seta. Endopod directed medially; first segment with lateral margin ornamented with distal tuft of fine pinnules; second segment elongate, with thickened lateral margin ornamented with row of spinules along outer edge; all setae plumose.

Leg 3 pair fused with expanded, flattened intercoxal sclerite, to form broad transverse plate (Fig. 6B). Intercoxal sclerite with extensive flap of membrane along posterior margin. Coxa and basis incompletely fused, with partial suture line on ventral surface marking plane of fusion and ornamented with two patches of fine denticles on ventral surface: large plumose (coxal) seta lo- cated posteriorly. Basis with plumose outer seta; posterior and lateral margins each with flap of membrane. Rami originating close together on basis, base of exopod concealed ventrally by flap-like velum, ornamented with fine spinules along free margin. Exopod broad, 2-segmented; first segment short and highly sclerotized, with small inner plumose seta plus large, reflexed, curved, outer spine lying transversely across ventral surface of ramus. Second segment compound, longer than wide, armed with 4 stout, naked outer spines (Fig. 6B, C) plus 5 short, plumose inner setae. Endopod 2-segmented, comprising small, unarmed proximal segment and medially-directed distal segment armed with 6 plumose setae (Fig. 6B). 


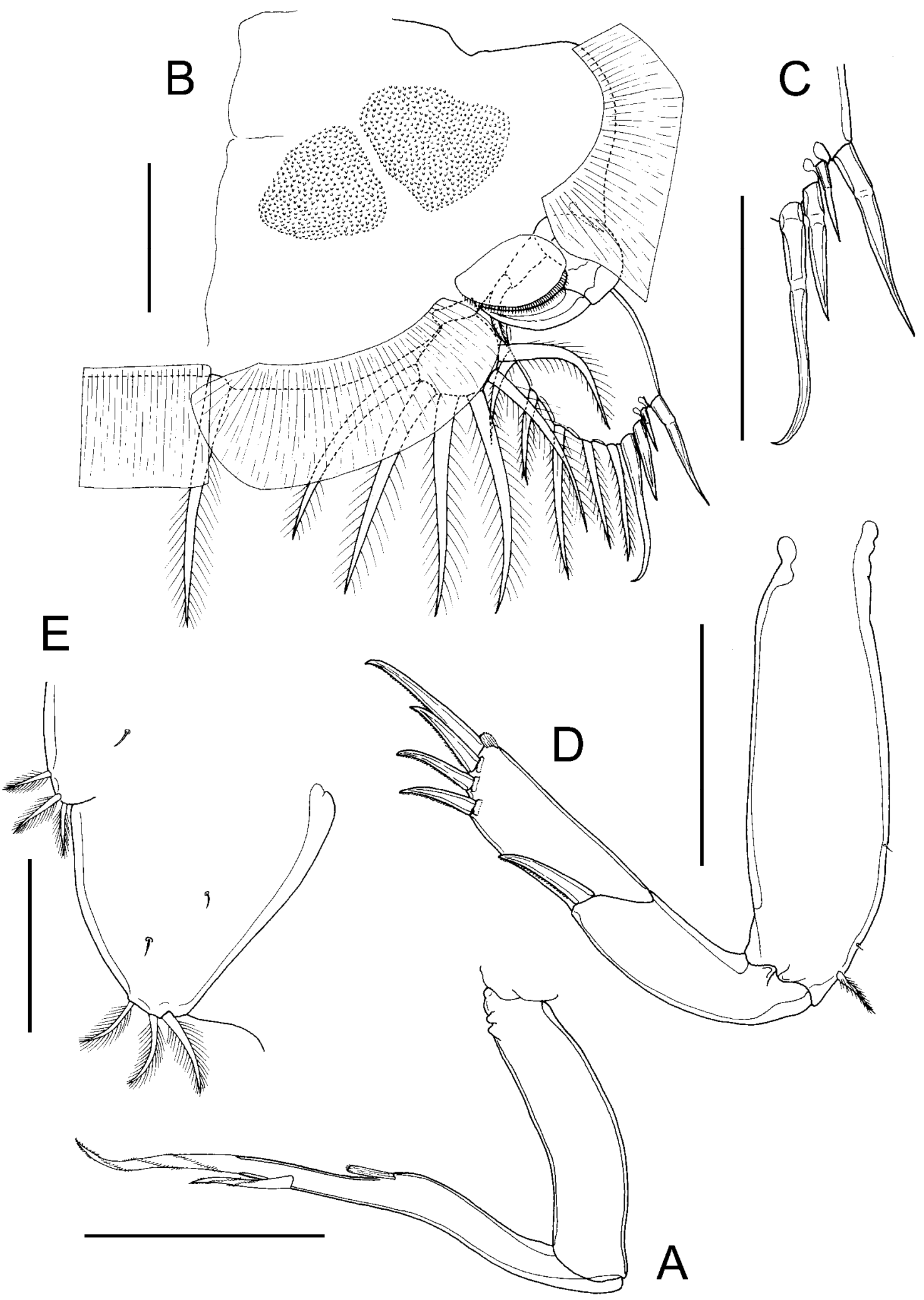

Fig. 6. Alanlewisia fallolunulus (Lewis, 1967), female (A-D). A - maxilla, ventral; B - leg 3, ventral; C - detail of exopodal outer margin spines on leg 3, ventral; D - leg 4; E - male legs 5 and 6, in situ. Scale bars: A, D = $200 \mu \mathrm{m} ; \mathrm{B}, \mathrm{C}, \mathrm{E}=100 \mu \mathrm{m}$. 
Leg 4 uniramous (Fig. 6D); coxa and basis fused, bearing small plumose basal seta laterally and ornamented with 2 sensillae distally on outer margin. Exopod 2-segmented. First exopodal segment with outer spine. Distal segment compound, representing second and third segments, bearing total of 4 unipectinate outer spines (Fig. 6D), distalmost longest; each spine with tiny pecten at base.

Leg 5 represented by 4 plumose setae carried on surface of genital complex - comprising isolated outer basal seta on lateral surface of genital complex plus 3 (exopodal) plumose setae located posterior and medial to isolated seta. Curved, J-shaped process about $50 \mu \mathrm{m}$ long located near postero-lateral angle of genital complex (Fig. 3C). Leg 6 represented by paired, unarmed lobes closing off genital apertures.

Male

Figs. 1B, D, 5B, C, 6E

Male body (Fig. 1B) dorsoventrally flattened; mean body length $2.45 \mathrm{~mm}$, (range $2.27-2.63 \mathrm{~mm}$, based on 3 specimens); maximum width of cephalothoracic shield $1.26 \mathrm{~mm}(1.12-1.40 \mathrm{~mm})$. Cephalothorax as in female. Frontal plates unmodified (Fig. 1D), possessing marginal membrane and dorsal sensilla but lacking ventral integumental flap. Genital complex longer than wide; mean length $0.62 \mathrm{~mm}(0.57-0.64 \mathrm{~mm})$ and mean width $0.43 \mathrm{~mm}(0.40-0.47 \mathrm{~mm})$. Abdomen comprising single somite (Fig. 1B) about as wide as long, mean length $0.15 \mathrm{~mm}(0.13-0.18 \mathrm{~mm})$ and mean width $0.16 \mathrm{~mm}$ $(0.15-0.17 \mathrm{~mm})$.

Antenna (Fig. 5B) uniramous, ornamented with large, weakly corrugated ridged pad on ventral surface of basis. Terminal subchela formed by endopodal segment carrying large digitiform accessory process, giving bifid appearance; armed with 2 naked setae. Postantennal process longer than in female, ornamented with fine surface striations (Fig. 5C).

Leg 5 (Fig. 6E) represented by lobe on posterolateral margin of genital complex armed with 3 plumose setae. No J-shaped process in male. Leg 6 (Fig. 6E) represented by large, lobe-like genital operculum closing off genital apertures; armed with 3 plumose setae.

H o s t : Naso unicornis (Forsskål, 1775) (Acanthuridae: Perciformes).

Site of infection: Gills.

L o c a 1 i t y : Îlot Goëland, Îlot La Régnière, Récif Tué, off Nouméa, New Caledonia.

De position of materia l: Stored in alcohol and deposited in the collections of Muséum national d'Histoire naturelle, Paris, 8 우우 and $1 \delta^{\hat{\gamma}}$ Reg. Nos. MNHN-Cp2439 (2우우 from JNC 1553) and MNHN-Cp2440 (6우우, 10 from JNC 1516), and in the collections of the Natural History Museum, London, $99+, 3 \widehat{\partial} \widehat{o}$ and 2 preadult females Reg. Nos. BMNH 2008.970-979 (from JNC 1552, 1580 1581, 2155).

\section{DISCUSSION}

The most remarkable feature of the new genus is the modified frontal plates of the female. Although each frontal plate is dorsoventrally flattened, it is produced into a rounded frontal expansion near the base of the antennule. An ovoid structure, which follows the curve of this expansion, is defined on the ventral surface of the plate by marginal sutures posteriorly and by a flaplike membrane antero-medially (Fig. 3A). These paired structures, present in females of the new genus, are not lunules and are interpreted here as an independently derived, attachment-enhancing modification. Lunules are subcircular organs located on the ventral surface of the frontal plates in both sexes. Each comprises a central concave area surrounded by a marginal zone with finescale radial ridges (see, for example, Cressey and Boyle Cressey 1979: fig. 41e). The presence of lunules on the frontal plates of the cephalothorax was used a key synapomorphy of the 16 genera comprising the subfamily Caliginae (cf. Boxshall and Halsey 2004).

The basal genera of the family Caligidae have a biramous first leg with a well-developed, 2-segmented endopod with the setal formula $0-0,3$. This state is retained in only four genera, Alebion Krøyer, 1863, Euryphorus Milne Edwards, 1840, Pupulina van Beneden, 1892 and Avitocaligus, and is also widely exhibited in related caligiform families such as the Dissonidae (see Boxshall et al. 2008 for SEM of leg 1 endopod), Cecropidae, Pandaridae and Trebiidae. In the genus Gloiopotes Steenstrup et Lütken, 1861 the endopod is also 2segmented and the distal segment carries 3 setae but the entire ramus is tiny and the setae are minute. Functionally, this limb appears to be effectively uniramous as in most other caligid genera in which the endopod is a vestigial lobate process. The new genus exhibits a novel and intermediate condition for the endopod of the first leg. Although unsegmented, the endopod is well developed and carries 2 long sparsely-plumose setae plus a short spine-like element apically. The setae are longer than the ramus. The reduction of the 3 posterior margin plumose setae on the distal exopodal segment of leg 1 is similar to that found in some members of the group of Caligus species related to C. productus Dana, 1852 (Boxshall and Gurney 1980).

The apparently double nature of the sternal furca is an interesting character. Other caligids, for example many species of Lepeophtheirus, have divided tines on a sternal furca that appears bifid in females and in males, but in Alanlewisia the furcal tines are simple and a pair of auxiliary spinous processes is present on the ventral body surface immediately adjacent to the furca. Some other caligids, such as Caligus coryphaenae Steenstrup et Lütken, 1861, have small rounded processes in this position but the presence of well-developed processes is a unique feature of this species. 
The presence of the paired, J-shaped process at the posterolateral corner of the genital complex of the adult female is also unique for the Caligidae. These processes are located adjacent to the row of 3 plumose setae representing the exopod of the fifth leg, but appear to be novel structures. They are present in females only but their function is unknown.
Acknowledgements. Thanks are due to Jean-Lou Justine (Institut de Recherche pour le Développement, Nouméa, Nouvelle Calédonie) who collected the material on which this paper is based, and made it available for study. I am grateful for the comments of Bob Kabata on the unusual features of this genus and for the improvements suggested by the reviewers.

Dissonidae (Copepoda: Siphonostomatoida). Syst. Parasitol. 70: 81-106.

CRESSEY R.F., BOYLE CRESSEY H. 1979: The parasitic copepods of Indo-West Pacific lizardfishes (Synodontidae). Smithson. Contr. Zool. 296: 1-71.

Froese R., PAuly D. (Eds.) 2007: FishBase. World Wide Web electronic publication. www.fishbase.org [24 July 2007].

Ho J.-S., LIN C.-L. 2000: Anuretes grandis sp. n., a caligid copepod (Siphonostomatoida) parasitic on Diagramma pictum (Pisces) in Taiwan, with discussion of Anuretes Heller, 1865. Folia Parasitol. 47: 227-234.

Huys R., BOXShall G.A. 1991: Copepoda Evolution. The Ray Society, London, $468 \mathrm{pp}$.

LEWIS A.G. 1967: Copepod crustaceans parasitic on teleost fishes of the Hawaiian Islands. Proc. U.S. Natl. Mus. 121: 1-204. 